\title{
QUALITY IMPROVEMENT The Second Conversation project: Improving training in end of life care communication among junior doctors
}

\author{
Authors: Rammya Mathew, ${ }^{\mathrm{A}}$ Anna Weil, ${ }^{\mathrm{B}}$ Katherine E Sleeman, ${ }^{\mathrm{C}}$ Katherine Bristowe, ${ }^{\mathrm{D}}$ Praphull Shukla, ${ }^{\mathrm{E}}$ Rebekah \\ Schiff, ${ }^{\mathrm{F}}$ Lucy Flanders, ${ }^{\mathrm{G}}$ Pauline Leonard, ${ }^{\mathrm{H}}$ Ollie Minton, ${ }^{\mathrm{I}}$ Dominique Wakefield, ${ }^{\mathrm{J}}$ Kimberley St John ${ }^{\mathrm{K}}$ and Irene Carey ${ }^{\mathrm{L}}$
}

Junior doctors describe a need for greater support and training in end of life care (EoLC) communication skills. The Second Conversation project was designed by a multi-professional steering group as a workplace based training intervention for junior doctors to improve their skills and confidence in undertaking EoLC conversations. Qualitative interviews were carried out with 11 junior doctors and five senior doctors across two sites who took part in, or facilitated, a 'second conversation'. This is a three-step training intervention that involves 1) observation - the junior doctor observes an EoLC conversation between a senior doctor and patient/caregiver; 2) direct experience - the junior doctor undertakes a followup second conversation with the patient/caregiver; and 3) reflection - the junior doctor discusses and reflects on the experience with a senior colleague. Interviews were analysed using framework analysis and findings informed iterative changes to the intervention and its implementation using 'Plan, Do, Study, Act' cycles. Benefits that were identified included the flexibility of the intervention and its positive impact on the confidence and skills of junior doctors. The

Authors: ${ }^{\text {A }}$ general practitioner, Wembley Park Drive Medical Centre and Islington GP Federation, Wembley, UK; ${ }^{\text {B }}$ palliative medicine specialist registrar, North London Hospice and Cicely Saunders Institute of Palliative Care, Policy \& Rehabilitation, London, UK; ${ }^{C}$ NIHR clinician scientist in palliative medicine, Cicely Saunders Institute of Palliative Care, Policy \& Rehabilitation, London, UK; ${ }^{D}$ Herbert Dunhill lecturer, Cicely Saunders Institute of Palliative Care, Policy \& Rehabilitation, London, UK; Econsultant physician and geriatrician, Darent Valley Hospital, Dartford, UK; F consultant in geriatrics and general medicine, Guy's and St Thomas' Hospital,

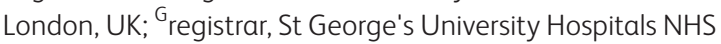
Foundation Trust, London, UK; ${ }^{\mathrm{H}}$ consultant medical oncologist, Whittington Health NHS Trust; ${ }^{\mathrm{I}}$ Macmillan consultant in palliative medicine, Brighton and Sussex University Hospitals NHS Trust, Brighton UK; ${ }^{j}$ palliative medicine specialty registrar, Guy's and St Thomas' Hospital, London, UK; ' Kransforming end of life care lead, Guy's and St Thomas' Hospital, London, UK; ' ${ }^{\text {consultant in }}$ palliative medicine, Guy's and St Thomas' Hospital, London, UK
Second Conversation was felt to be of most value to newly qualified doctors and worked well on wards where length of stay was longer and EoLC conversations frequently happen. Further evaluation and exploration of patient and caregiver experiences is required.

KEYWORDS: Palliative, end of life, medical education, communication skills

\section{Introduction}

High-quality end of life care (EoLC) discussions allow patients to make informed decisions about their care, set goals and priorities, and prepare for their death. ${ }^{1}$ Conversely, poorly handled conversations around EoLC are a common source of complaints and can cause unnecessary distress. ${ }^{2}$ The British Medical Association report into EoLC reveals a clear desire among doctors for greater support and training in this area. ${ }^{3}$ This is particularly pertinent to junior doctors working in the acute setting, who have previously reported that they do not always feel adequately prepared or supported to undertake EoLC conversations with patients and families. ${ }^{4,5}$ The literature highlights a feeling among junior doctors of 'being left' to care for dying patients and draws attention to concerns they have voiced around making a sensitive situation worse as a result of their inexperience. ${ }^{4,6}$

'Learning by observation' and 'learning by doing' have been shown to be effective methods to improve confidence and competence in EoLC communication skills, ${ }^{6}$ but isolated educational interventions often lack sustainability and reach. We hypothesised that an EoLC communication skills training intervention that can be embedded in everyday clinical practice would be more sustainable than other interventions, such as simulation or role play, that are traditionally used in both undergraduate and postgraduate training. ${ }^{7}$

The primary aim of this project was to develop a workplace-based training intervention that would give junior doctors the opportunity to practice and refine their EoLC communication skills.

The secondary aims were to:

> explore how the intervention is implemented in practice

$>$ explore the views of junior doctors (participants) and senior doctors (facilitators) regarding the intervention 
$>$ identify the drivers and barriers to embedding the intervention in practice and use these insights to support improved implementation.

\section{Methods}

A multi-professional and multi-organisation steering group was established to develop the training intervention in December 2016. This included a project lead from the Royal College of Physicians and site leads from each of the three participating acute London NHS trusts.

Based on existing literature ${ }^{4,6,8}$ and observed practice, the steering group deemed the following to be essential components/ qualities of a sustainable EoLC skills training intervention aimed at junior doctors:

$>$ learning by observation

$>$ learning by doing

$>$ feedback and/or reflection, ideally facilitated by someone experienced in EoLC communication

$>$ intervention to be work-place based

$>$ to not require significant additional monetary or time resource to be delivered.

Once developed, the intervention, was badged the 'Second Conversation' because it involves junior doctors observing an initial EoLC conversation and then leading a follow-up 'second conversation' with patients/caregivers. The intervention was tested with junior doctors so that it could be further refined and lessons could be learnt about how best to implement it in practice.

\section{Quality improvement strategy}

Site leads in each of the trusts were responsible for identifying appropriate clinical areas to pilot the Second Conversation and for promoting use of the intervention locally. They also provided feedback to the steering group on the barriers and facilitators to embedding the Second Conversation in their respective clinical areas. The steering group convened on three occasions between December 2016 and August 2017, in order to refine and improve the implementation of the Second Conversation. The 'Plan, Do, Study, Act' (PDSA) framework (Fig 1) was used to support this approach.

The 'Plan' phase involved the design of the Second Conversation intervention and promotion of the intervention in chosen clinical areas at each of the participating sites.

The 'Do' phase involved case by case testing of the intervention with individual junior doctors.

The 'Study' phase involved the steering group reflection on case by case testing with junior doctors, resulting in iterative changes to the process of implementation (the 'Act' phase). Feedback came informally from site leads and more formally from semi-structured participant interviews, described more fully below. Provisional analysis supported the PDSA cycles of change.

\section{Semi-structured interviews}

Junior and senior (consultant or registrar) doctors who had taken part in Second Conversation were recruited by site leads to take part in semi-structured interviews. The study was explained, written informed consent was taken from interviewees and

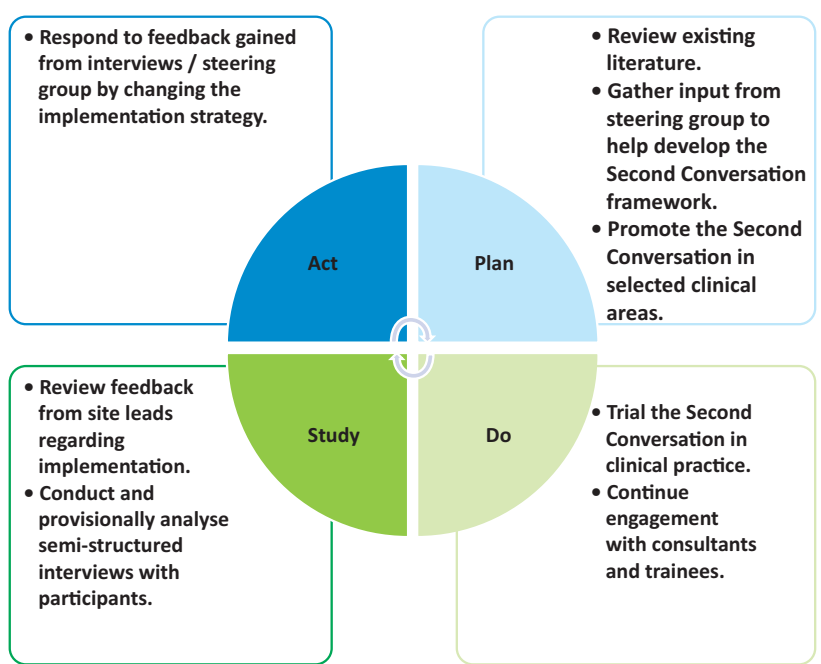

Fig 1. The Plan, Do, Study, Act approach

telephone interviews were conducted. Semi-structured interviews using a topic guide with open questions allowed the interviewer to explore the narratives of junior doctors as participants and senior doctors as facilitators. Junior doctor participants received a $€ 5$ Amazon voucher for taking part in an interview (ethical approval attained via the Health Research Authority, IRAS no. 220965). The interviews were audio-recorded, transcribed verbatim and anonymised using pseudonyms.

\section{Qualitative analysis}

The semi-structured interviews were subsequently analysed using a framework analysis method, which involved familiarisation with the data; inductive and deductive coding; development of a framework; application of the framework; data charting; and interpretation of the data. ${ }^{9}$ This provided a means of exploring the experiences of individual interviewees and comparing similarities and differences in perspectives, both across and between the junior and senior doctor groups. The data was organised using NVivo 11 software. ${ }^{2}$ The data was coded and a selection of interviews were cross-checked in order to ensure reliability and rigour.

\section{Results}

The steering group developed the Second Conversation training intervention using the principles that 'learning by observation' and 'learning by doing' are known to be effective methods to improve confidence and competence in EoLC communication skills. ${ }^{6}$ The training intervention incorporates active observation, experiential learning and facilitated feedback and/or reflection (see Fig 2).

In clinical practice, initial EoLC conversations are usually led by a senior doctor (consultant or registrar). The Second Conversation proposes that a subsequent EoLC conversation should occur soon afterwards, led by a junior doctor, affording them the opportunity to build their skills and confidence in EoLC communication, giving patients and caregivers the opportunity to revisit the discussion and clarify any questions or concerns 


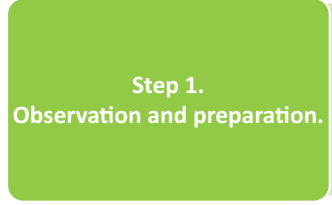

- Active observation of an end of life care conversation between a senior doctor and patient/caregiver.

- Debrief with a senior colleague, focusing on what questions or concerns may arise in a second conversation.

Step 2. Experiential learning.$$
\text { Step } 3 .
$$

Facilitated reflection with

a senior colleague, covering the following.
- What went well?

-What could have gone better?

- What might you do differently?

Fig 2. Model describing three stages of the Second Conversation intervention

that may have arisen from the initial discussion. Following this, the junior doctor either receives direct feedback on their communication style and approach, or they reflect on their

experience with a senior doctor, discussing what went well, what could have gone better and what they might do differently going forwards. The subject of the EoLC conversations could involve any issues pertaining to EoLC, for example, withdrawing and withholding life sustaining treatment; discussing a change in focus from active treatment to 'best supportive care'; or discussing ceilings of treatment including do not attempt cardiopulmonary resuscitation discussions.

Case by case testing provided insights into how the Second Conversation intervention was used in practice. Table 1 sets out how the Second Conversation was used and interpreted in the context of clinical practice, including where and when the conversations took place, what topics were discussed and in what way the training and education component was employed.

\section{Semi-structured interviews}

Sixteen semi-structured interviews were carried out with junior and senior doctors working across elderly and acute medical specialties across two NHS trusts (the third trust failed to recruit participants; see Fig 3). Of the 11 interviews with junior doctors (JD1-11), nine were in their first year working as a doctor (foundation year 1 (F1)) and two were in their second (foundation year 2). Of the five senior doctors (Fac1-5), two were medical consultants and three were registrar level doctors (specialty trainee level 3 and above)

Table 1. How the second conversation worked in practice

\section{The first Setting conversation}

Topic of discussion

Training/education component

\section{The second Timing} conversation

Setting

Facilitator observation

Topic of discussion

Training education component: debrief Evidencing learning, skills development and reflection
Conversations took place during and after ward rounds, during on-call shifts or when the facilitator was on the ward supervising the junior doctor.

A range of topics were discussed in the first conversation:

$>$ clinical deterioration and poor prognosis

$>$ resuscitation decisions

$>$ new ceiling(s) of treatment

complex discharge

> other areas relating to advance care planning.

Where possible, a short discussion took place between the facilitator and junior doctor following the first conversation, which lasted between a few minutes to half an hour. This was used by junior doctors to ask questions and prepare and plan how to approach the second conversation.

Second conversations took place on the same day or a few days after the first conversation. There was one exception, which took place after two weeks (where the first conversation had taken place during an on-call shift).

Conversations were arranged in advance and usually took place either on the ward (face-toface), though some were done by telephone for the patient or caregiver's convenience.

> Three conversations were with the patient alone.

$>$ One conversation was with the patient and their caregiver.

$>$ Seven conversations were with the caregiver alone.

The second conversations were usually not observed.

Depending on the patient/caregiver's wishes and needs, the second conversation allowed time to revisit the first discussion and clarify understanding and answer any new questions.

Conversations were followed by informal or formal 'debriefs' which varied in length, depth and structure.

Junior doctors were able to use the Second Conversation as an opportunity to evidence curriculum items in their e-portfolio, in the form of a supervised learning event or structured reflection. 


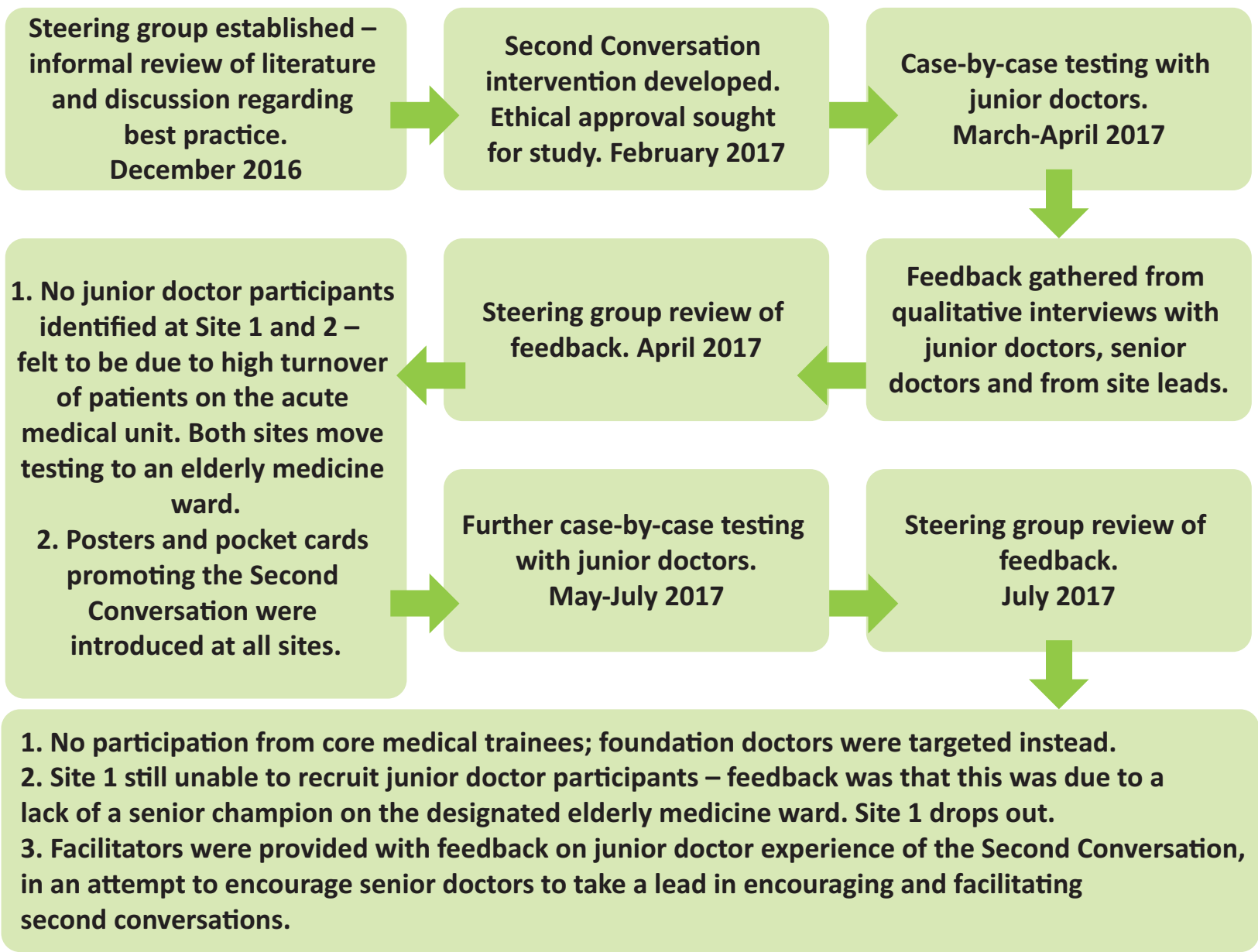

Fig 3. Chronology of quality improvement activity

working in either elderly medicine or palliative care. The telephone interviews lasted between 8 and 18 minutes, with a median time of 12 minutes. For the purpose of analysis, participants were each given a unique identification code, relating to their role of either junior or senior doctor, followed by a study number.

Framework analysis revealed four key findings: the Second Conversation provided junior doctors with a novel training opportunity; it addressed skills and confidence around EoLC communication skills; it promoted best practice; and it aligned with requirements for professional development.

\section{Provides a novel training opportunity}

Junior doctors who participated in a second conversation conveyed that this was a novel training experience for them and that it was one that allowed them to gain confidence in an area of medicine that they felt relatively inexperienced; JD2:

They are not really the conversations you get to have as a junior doctor, especially a F1, so it is definitely very good practice.

The senior doctors identified that by naming the process as a training intervention, perceptions of the situation seemed to change and juniors reacted differently to the situation, as one consultant said; Fac5:

It is good to formalise it - the Second Conversation - you know. Makes them perhaps think on it a bit more, about what they are going to say and listen a bit more to what we say, otherwise they might be more passive participants.

\section{Addresses skills and confidence of junior doctors}

Taking part in a second conversation allowed junior doctors to confront their worries about EoLC conversations. It also provided an opportunity for junior doctors to apply learning they had acquired from medical school to real-life situations; JD1:

You can take away things that you can use later on, and it helps break that barrier of talking about end of life.

and JD8:

At my university, I was taught to make sure you say the word 'dying', not to avoid that word. I've never used that word with a patient before, this was my first chance and it made me feel comfortable broaching it. 
They found value in being part of the first conversation, as this enabled them to approach the second conversation feeling better prepared; JD9:

I think it was more helpful because you have already gauged what the relative knows and what they want before you speak to them, so you have, you kind of know what you're going into rather than going in blind which I guess is the more scary thing when you're having those conversations...so it's definitely more comforting going in for the second time.

Overall the Second Conversation intervention improved junior doctors' confidence and made them feel able to participate in further EoLC discussions; JD6:

I think probably this exercise did improve my confidence... because I've been and done more similar conversations since. I think now I've actually made a step forward in the way I can sort of frame the discussion.

\section{Promotes best practice and patient-centred care}

Interviewees identified that the Second Conversation promoted best practice. The second conversation often revealed that patients/caregivers had not fully understood or digested what had been discussed in the first conversation, and this reinforced the importance of a follow-up discussion; Fac5:

To be honest, in a way, this is almost like emulating what would be best practice.

\section{and JD8:}

The first thing I realised with the second consultation was that they had forgotten the vast majority of the conversation from the day before.

The second conversation allowed patients and their caregivers to seek clarity; JD3:

So, they came in then with their list of questions, which they hadn't thought of at the time...It meant a lot for them to have answers...It did seem that they really appreciated having that reiteration and extra time to go through everything.

Junior doctors seemed to value the opportunity to show empathy and support; JD1:

We were updating them and showing that we cared about them in that time when it's a delicate situation day-to-day.

\section{Aligns with requirements for professional development}

The Second Conversation was an opportunity to complete learning events using the e-portfolio. One junior doctor said; JD10:

\section{[It was] a good way of demonstrating fields of competencies.}

They also referred to using the Second Conversation repeatedly to build and develop skills; JD3:

The more I observe people having those difficult conversations, the more I garner from them, and the more practice you have, the better you get, and the more opportunity you have to debrief, the more skills you learn.
Interestingly, senior doctors also felt that the reflective component was an opportunity for their own self-reflection and learning; Fac4:

I suppose it's good for us in doing so as well to reflect on how we approach it.

Challenges were, however, identified when trying to embed the Second Conversation in routine clinical practice; efforts were made to mitigate these where possible by influencing behaviours and attitudes (see Table 2). Changes that resulted from the PDSA cycles of testing are outlined in Fig 3.

\section{Discussion}

Preliminary evaluation suggests that the Second Conversation is a practical and beneficial training intervention that can be embedded into day-to-day clinical practice. Many of the anticipated training benefits were demonstrated, with foundation doctors reporting that it improved both their confidence and competence around EoLC communication. In addition, junior doctors seemed to value the opportunity to show empathy and build relationships with patients and their caregivers, which was an unexpected but positive finding.

Feedback also suggests that the Second Conversation offered additional training elements that role-play and simulation methods do not provide, for example, junior doctors referred to it 'breaking the barrier' of talking about end of life and feeling comfortable to use the word 'death' in a real-life conversation. Although simulation and role play have been advocated as a means of offering a safe, 'low-risk' learning environment, ${ }^{10,11}$ junior doctors who took part in a second conversation did not report feeling out of their depth; as it would appear that being part of the initial conversation offered time to prepare and also helped develop a sense of familiarity with the situation. However, the results of a recent systematic review assessing the effectiveness of EoLC communication skills showed that the impact on trainee behaviours was greater in simulated interactions rather than 'real-life' interactions. ${ }^{12}$ Further consideration of the potential effects of the Second Conversation on behaviours, as well as confidence, is required.

Overall, junior doctors also perceived the Second Conversation to be a positive experience for patients and caregivers. One of the perceived benefits was that the clinical team were proactively communicating with patients/caregivers. It is now widely acknowledged that EoLC discussions should not be viewed as a one-off event but a series of conversations, ${ }^{13,14}$ and it would appear that a planned second conversation led by a junior doctor can facilitate this approach. Junior doctors also alluded to the fact that it gave patients and caregivers the opportunity to clarify their understanding of the first conversation, which was often incomplete. This is supported by the literature, which shows that $40-80 \%$ of medical information presented to patients is forgotten almost immediately, particularly after breaking 'bad news', and the greater the amount presented, the lower the proportion recalled. ${ }^{15}$

There was an area where senior and junior doctors consistently differed in terms of their views of the Second Conversation. Senior doctors felt that the second conversation was already happening in everyday clinical practice, but recognised there were benefits to formalising the process and highlighting it as a training opportunity. Junior doctors, however, felt the Second Conversation 
Table 2. Barriers and mitigating factors to embedding the Second Conversation in practice - and how this learning fed into the quality improvement strategy for improved implementation

\begin{tabular}{|c|c|}
\hline Barrier & Quote \\
\hline $\begin{array}{l}\text { Senior doctors } \\
\text { not recognising } \\
\text { the need for } \\
\text { formal training } \\
\text { and often having }\end{array}$ & $\begin{array}{l}\text { Fac3, 'It will take time for senior } \\
\text { members of staff to recognise } \\
\text { how important this is... it's a } \\
\text { matter of recognising that this i } \\
\text { also part of training.' }\end{array}$ \\
\hline $\begin{array}{l}\text { limited experience } \\
\text { in having end of } \\
\text { life conversations } \\
\text { themselves. }\end{array}$ & $\begin{array}{l}\text { JD6, 'I suppose you may have } \\
\text { seniors who may not themselves } \\
\text { be having these discussions } \\
\text { that often, so they may be less } \\
\text { confident sort of observing you.' }\end{array}$ \\
\hline $\begin{array}{l}\text { Heavy workloads, } \\
\text { poor staffing levels } \\
\text { and changing shift } \\
\text { patterns. }\end{array}$ & $\begin{array}{l}\text { JD3, 'It's not impossible but } \\
\text { you are looking at three or four } \\
\text { separate people's timings and } \\
\text { that's probably the only barrier, } \\
\text { but if you persist it works.' }\end{array}$ \\
\hline
\end{tabular}

Forgetting
to identify
opportunities

Patients and caregivers not wanting to or not being able to engage in a second conversation. remember everything that $\mathrm{x}$ had said. So, it is useful, but it would probably be of more benefit to other patients who might have

\section{Mitigating factors}

Even observing poor communication can be helpful, if the junior doctor is insightful and uses this to reflect on their own approach; JD3, 'It's always interesting to observe the first conversation because I think it's impossible to not sit there and think, oh ok, I might not have said it in that way, or, oh, that's a better way than I would have said it.'

There was a view that even if the feedback and reflection process was 'light touch', it was still useful for junior doctors; Fac5: 'Well it's better than nothing and its only light touch because he told me that it was fine, we did this and that, if there was more of a problem I would have spent more time with him.'

Junior doctors who have a positive experience then proactively seek out opportunities themselves; JD3: '[The Second Conversation experience] made me think that when I have a conversation, maybe to reach out and ask, maybe to discuss it for a few minutes at least...It would make me do that more often because I realise you get an awful lot out of that.'

JD2, 'This patient in particular was not...Didn't really engage. He was obviously quite depressed. He did more questions after a period of being able to think about it.'
Only one trainee reported that the patient got little out of the Second Conversation. Mostly trainee perception was that patients/families appreciated the ongoing communication; JD7: 'But I think in that situation [the second conversation] was really helpful because it gave real clarity to it and also gave them an opportunity to ask questions.'

\section{Iterative learning that fed into} quality improvement strategy

Provide informal feedback to facilitators on how their trainees found the Second Conversation experience.

To begin with, introduce the Second Conversation onwards where end of life conversations take place more frequently.

Accept that clinical areas with a high turnover of patients, where junior doctors are working irregular shift patterns (eg the acute medical unit) may not be the best place to use the Second Conversation.

Reiterate to potential participants that it is not essential for the second conversation to be observed.

Implement reminders - pocket cards, posters and use local ward champions to engage trainees and facilitators in the Second Conversation.

Undertake in-depth interviews with patients and caregivers about their experience of being part of the Second Conversation, to further explore their views and identify any concerns. was novel and offered them an experience that they had not previously had. The reason for the perceived difference between these groups may be that clinical supervisors underestimate the fear and lack of confidence that many new doctors have around EoLC communication and do not recognise the limited exposure they have to these conversations during undergraduate training, ${ }^{16}$ or do not routinely invite active observation of their practice.

\section{Reflections from the quality improvement approach}

The quality improvement (QI) approach provided valuable insights around the implementation of the Second Conversation, identifying important learning about what the right environment is for its use. Of note, although three trusts were recruited to the study, only two of the three managed to engage junior and senior doctors. The reason for this is that it was initially piloted on the acute medical unit at the third site, and due to the nature of shift work and the rapid turnover of patients, junior doctors were unable to find opportunities to take part in a second conversation; a finding also mirrored in evaluations of other complex interventions in the acute hospital setting. ${ }^{17}$ Factors, such as having an active junior doctor site lead and an engaged consultant champion, seemed to influence the uptake of the Second Conversation. This is typical of change initiatives, where the role of the champion 
is often essential to getting buy-in from all those who might be impacted by a new intervention. ${ }^{18}$

\section{Strengths and limitations}

The Second Conversation was initially aimed at foundation and core trainees; the lack of uptake among core trainees is most likely multifactorial. One of the participating wards had no core trainees and feedback from another site was that core trainees were already initiating EoLC conversations with patients and so the perception was that the Second Conversation was of limited benefit to them.

An advantage of the Second Conversation is that it does not require additional time away from the clinical setting, and it has the scope to be captured in a mini-clinical evaluation exercise assessment (mini-CEX). This is an important consideration as trainees have reported that increasing service demands are impacting on their ability to engage in training opportunities outside the clinical setting, such as formal classroom based teaching sessions. ${ }^{19}$ However, this also means that there is no built-in protected time to undertake a second conversation; it has to fit in with scheduled clinical work and this can be challenging for junior doctors, particularly when there are both competing clinical priorities and other training requirements that need to be fulfilled. This is, however, no different to the challenges faced with other types of workplace-based assessment, for which trainees have reported difficulty in completing assessments, both due to lack of protected training time and variable availability of their supervisors. $^{20}$

This piece of work combines QI methodology with preliminary qualitative analysis to develop a training intervention and understand how it might be best used in clinical practice. Limitations of the study include uncertainty about the exact number of junior doctors who took part in the Second Conversation project, as recorded numbers only include those who informed the site lead of their experience and subsequently offered to be interviewed as part of the study. Participation and feedback by junior doctors was voluntary, therefore the study may be subject to self-selection bias; junior doctors with 'more than average' levels of competence or more interest in communication being more likely to take part in a second conversation. Selfselection bias is a common feature of studies aiming to evaluate communication skills ${ }^{21}$ and it is difficult to overcome when participation is voluntary. Finally, the study did not directly elicit the views of patients and caregivers, and so limited conclusions can be drawn at this stage about the added value that a second conversation offers to them. Further research should explore the views of patients/caregivers regarding the intervention, and the impact and quality of the conversations they experienced.

\section{Conclusion}

The Second Conversation was viewed as an acceptable training intervention by both junior and senior doctors. It appears to be of most value to foundation doctors, and works well on wards where patient stay is longer and where EoLC conversations happen frequently. The major advantage of the Second Conversation is that it offers real-life experience and it can be used flexibly in the ward environment. Like many other work place based teaching and assessment methods, junior and senior doctors often find it difficult to make time for these opportunities, alongside their demanding clinical roles. However, it ties in with best practice, which advocates that EoLC conversations should be a continuous process and not a standalone event. Furthermore, if the benefit to patients and caregivers can be confirmed on further evaluation then there would be a strong argument to make the Second Conversation part of routine practice.

\section{Future work}

The next phase of this work involves evaluating the impact of the changes made in this first phase of implementation by recording the adoption and spread of the intervention at existing and new clinical sites. A larger qualitative interview study is also currently underway to further explore the experiences of the Second Conversation in more depth from the perspective of patients, caregivers, senior and junior doctors.

\section{Research funding}

The Royal College of Physicians sponsored this study.

\section{References}

1 Chung H-O, Oczkowski SJW, Hanvey L, Mbuagbaw L, You J]. Educational interventions to train healthcare professionals in endof-life communication: a systematic review and meta-analysis. BMC Med Educ 2016;16:131. http://bmcmededuc.biomedcentral. com/articles/10.1186/s12909-016-0653-x [Accessed 29 April 2018].

2 Riley J. A strategy for end of life care in the UK. BMJ 2008;337:a943. www.bmj.com/content/337/bmj.a943.long [Accessed 29 April 2018].

3 British Medical Association. End-of-life care and physician-assisted dying. London: BMA, 2016. www.bma.org.uk/connecting-doctors/ policy_debate/end-of-life_care_and_physician_assisted_dying/m/ elcpad [Accessed 29 April 2018].

4 Bowden J, Dempsey K, Boyd K, Fallon M, Murray SA. Are newly qualified doctors prepared to provide supportive and end-of-life care? A survey of Foundation Year 1 doctors and consultants. J $R$ Coll Physicians Edinb 2013;43:24-8. http://www.rcpe.ac.uk/journal/ issue/journal_43_1/bowden.pdf [Accessed 29 April 2018].

5 Sleeman K. End-of-life communication: let's talk about death. J $R$ Coll Physicians Edinb 2013;43:197-9. www.rcpe.ac.uk/sites/default/ files/Sleeman.pdf [Accessed 12 July 2018].

6 Price S, Schofield S. How do junior doctors in the UK learn to provide end of life care: a qualitative evaluation of postgraduate education. BMC Palliat Care 2015;14:45. http://bmcpalliatcare.biomedcentral. com/articles/10.1186/s12904-015-0039-6 [Accessed 29 April 2018].

7 Perron NJ, Sommer J, Hudelson P et al. Clinical supervisors' perceived needs for teaching communication skills in clinical practice. Med Teach 2009;31:e316-22.

8 Tulsky JA, Chesney MA, Lo B. See one, do one, teach one? House staff experience discussing do-not-resuscitate orders. Arch Intern Med 1996;156:1285-9. https://jamanetwork.com/journals/ jamainternalmedicine/fullarticle/vol/156/pg/1285 [Accessed 12 July 2018].

9 Gale NK, Heath G, Cameron E, Rashid S, Redwood S. Using the framework method for the analysis of qualitative data in multidisciplinary health research. BMC Med Res Methodol 2013;13:117.

10 Smith MB, Macieira TGR, Bumbach MD et al. The use of simulation to teach nursing students and clinicians palliative care and end-of-life communication: a systematic review. Am J Hosp Palliat Med 2018;35:1140-54. http://journals.sagepub.com/ doi/10.1177/1049909118761386 [Accessed 29 April 2018]. 
11 Shaw PA, Abbott MA. High-fidelity simulation: Teaching end-of-life care. Nurse Educ Today 2017:49:8-11.

12 Selman LE, Brighton LJ, Hawkins A et al. The effect of communication skills training for generalist palliative care providers on patient-reported outcomes and clinician behaviors: a systematic review and meta-analysis. J Pain Symptom Manage 2017;54:404-416.e5. www.jpsmjournal.com/article/S08853924(17)30311-1/pdf [Accessed 29 April 2018].

13 Larson DG, Tobin DR. End-of-life conversations. JAMA 2000;284:1573. http://jama.jamanetwork.com/article. aspx?doi=10.1001/jama.284.12.1573 [Accessed 29 April 2018].

14 Brighton L], Bristowe K. Communication in palliative care: talking about the end of life, before the end of life. Postgrad Med J 2016;92:466-70. Available from: https://pmj.bmj.com/ content/postgradmedj/92/1090/466.full.pdf [Accessed 01 May 2018].

15 Kessels RPC. Patients' memory for medical information. J R Soc Med 2003;96:219-22. www.ncbi.n/m.nih.gov/pmc/articles/ PMC539473/pdf/0960219.pdf [Accessed 29 April 2018].

16 Campbell R. Lessons learnt about end of life care. Student BMJ 2017. http://student.bmj.com/student/view-article.html?id=sbmj. j2929 [Accessed 12 July 2018].

17 Bristowe K, Carey I, Hopper A. Seeing is believing: healthcare professionals' perceptions of a complex intervention to improve care towards the end of life: A qualitative interview study. Palliative Medicine 2017:32:525-32.
18 National Institute for Health and Clinical Excellence. How to change practice: Understand, identify and overcome barriers to change. London: NICE, 2007 www.nice.org.uk/media/default/ about/what-we-do/into-practice/support-for-service-improvement-and-audit/how-to-change-practice-barriers-to-change.pdf [Accessed 29 April 2018].

19 Tasker F, Newbery N, Burr B, Goddard AF. Survey of core medical trainees in the United Kingdom 2013 - inconsistencies in training experience and competing with service demands. Clin Med 2014;14:149-56. www.clinmed.rcpjournal.org/content/14/2/149. full [Accessed 29 April 2018].

20 Goh A, Massie J, Ali JM. Workplace based assessments - confusion and misuse continues to be a problem. Clin Med 2015;15:109. www.clinmed.rcpjournal.org/content/15/1/106.6.full [Accessed 29 April 2018]

21 Hulsman RL, Ros WJ, Winnubst JA, Bensing JM. Teaching clinically experienced physicians communication skills. A review of evaluation studies. Med Educ 1999;33:655-68 https://onlinelibrary.wiley.com/doi/abs/10.1046/j.13652923.1999.00519.x [Accessed 29 April 2018].

Address for correspondence: Dr Rammya Mathew, Wembley Park Drive Medical Centre, 21 Wembley Park Drive, Wembley, Middlesex HA9 8HD, UK.

Email: rammya.mathew@nhs.net

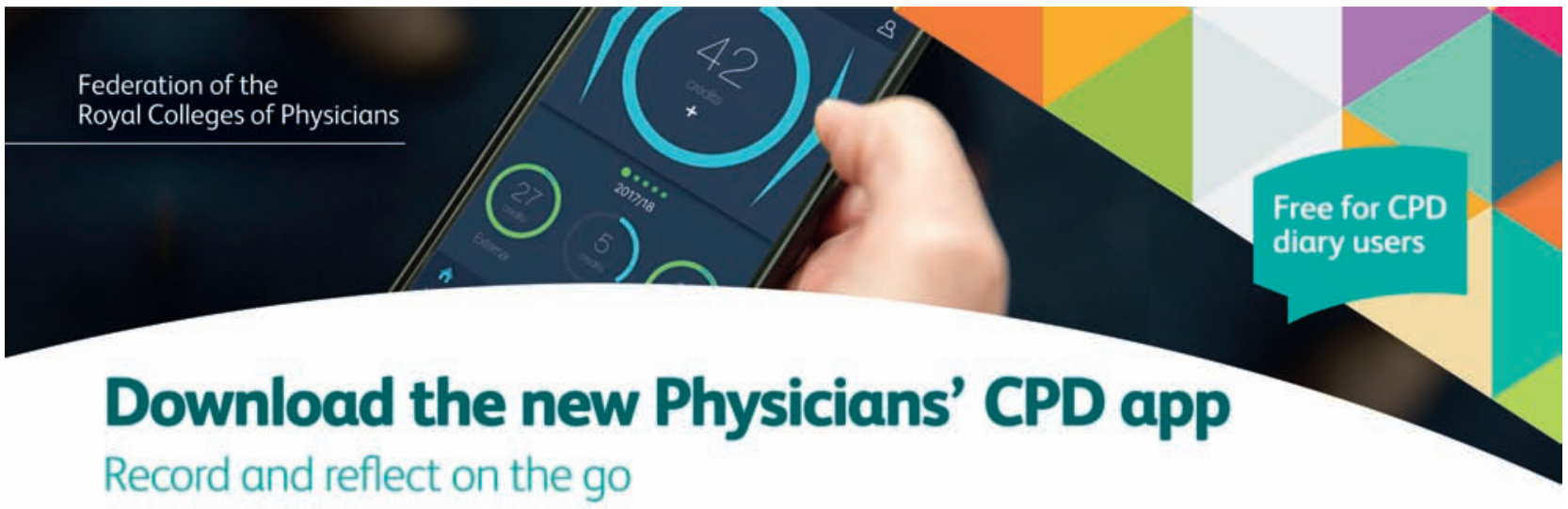

> Add and reflect on your educational activities, wherever you are - your changes will sync automatically with your online CPD diary ${ }^{*}$

$>$ Voice transcribe your development needs and reflections instantly

\author{
$>$ Access our list of over 5,000 approved activities \\ $>$ Keep track of your CPD and monitor \\ your progress to achieving your annual \\ credit requirements
}

Simply download the Physicians' CPD app on your smartphone or tablet today and log in using your CPD diary account details. Now available on the IOS App Store and the Google Play Store

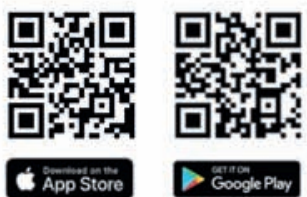

Physicians' CPD

https://cpd.rcplondon.ac.uk *Registration to the CPD diary is required to use the Physicians' CPD app.
'An excellent and user-friendly app. I shall be using my CPD diary more frequently now!'

Dr Andrew Lansdown, consultant endocrinologist 